\title{
Selective Liquid-Phase Semihydrogenation of Functionalized Acetylenes and Propargylic Alcohols with Silica-Supported Bimetallic Palladium-Copper Catalysts ${ }^{\dagger}$
}

\author{
Marieke P. R. Spee, ${ }^{\ddagger}$ J aap Boersma, $\neq$ Michel D. Meijer, ${ }^{\ddagger}$ Martijn Q. Slagt, $\neq$ \\ Gerard van Koten,*,‡ and J ohn W. Geus ${ }^{\S}$
}

Debye Institute, Department of Metal-Mediated Synthesis, Utrecht University, Padualaan 8, 3584 CH Utrecht, The Netherlands, and Debye Institute, Department of Inorganic Chemistry, Utrecht University, Sorbonnelaan 16, 3584 CA Utrecht, The Netherlands

g.vankoten@chem.uu.nl.

Received August 15, 2000

\begin{abstract}
Silica-supported, bimetallic palladium-copper catalysts were prepared in solution under mild conditions by reacting lithium di (4-tolyl)cuprate with palladium acetate in the presence of silica particles. Small bimetallic palladium-copper particles were deposited on the silica surface as confirmed with TEM-EDAX and EXAFS. The new material has been applied as catalyst in the liquid-phase semihydrogenation of mono- and disubstituted alkynes and showed high selectivity toward the cis-alkenes. The influence of addition of quinoline or potassium hydroxide to the semihydrogenation reaction mixture and the effects of exposure of the catalyst to air before use have been investigated.
\end{abstract}

\section{Introduction}

Alkynes are versatile reagents in organic synthesis since the $-\mathrm{C} \equiv \mathrm{CH}$ group can easily be used in the formation of new carbon-carbon bonds with retention of the triple bond. The $\mathrm{C} \equiv \mathrm{C}$ unit can beapplied in a broad range of subsequent reactions. In particular, the alkyne functionality can lead to a cis-alkene through stereoselective addition of hydrogen to form a double bond. This so-called semihydrogenation to form Z-alkenes is often an important step in industrial processes as well as in laboratory-scale reactions..$^{1,2} \mathrm{M}$ any synthetic intermediates resemble the propargylic alcohol structure, ${ }^{3-13}$ and organic compounds containing this structure are often used as probes for examining the semihydrogenation of the acetylenic bond. ${ }^{14,15}$

* To whom correspondence should be addressed. Tel. +31-302533120. Fax: +31-30-2523615.

+ Dedicated to Prof. G. J. M. van der Kerk in recognition of his important contributions to Organometallic Chemistry. Part of this work was initiated during the time that G.v.K. was in the Institute for Applied Chemistry (TNO) of which Prof. van der Kerk was Director. ₹ Department of M etal-Mediated Synthesis, Utrecht University.

$\S$ Department of I norganic Chemistry, Utrecht University.

(1) Gutman, H.; Lindlar, H. In Chemistry of Acetylenes; Viehe, H. G., Ed.; Marcel Dekker: New York, 1969.

(2) Marvell, E. N.; Li, T. Synthesis 1973, 457.

(3) Chaudhari, R. V.; J aganathan, R.; Kohle, D. S.; Emig, G.; Hofmann, H. Appl. Catal. 1987, 29, 141.

(4) Kearby, K. In Proc. 2nd Int. Congr. Catal. Paris 1960; Technip, Paris, 1961; p 2567.

(5) Sokol'skii, D. V.; Omarkulov, T. O.; Suyunbaev, U.; Kukasheva, A. A. Isv. Akad. Nauk. SSSR, Ser. Khim. 1980, 4, 29.

(6) Sokol'skii, D. V.; Omarkulov, T. O.; Mukataev, Zh.; Zhubanova,

L. K.; Babenkova, L. V. Kinet. Katal. (Engl. Transl.) 1985, 26, 643.

(7) Fisher, F. G.; Löwenberg, K Liebigs Ann. Chem. 1923, 475, 183.

(8) Ruzicka, L.; Firmenick, G. Helv. Chim. Acta 1939, 22, 392.

(9) Heilbron, I. M.; J ones, E. R. H.; McCrombie, J. T.; Weedon, B.

C. L. J . Chem. Soc. 1945, 84.

(10) Schinz, H.; Ruzicka, L.; Seidel, C. F.; Tavel, C. Helv. Chim. Acta $1947,30,1810$

(11) Heath, A. Chem. Eng. (N.Y.) 1973, 80, 48

(12) Izumi, Y.; Tanaka, Y.; Urabe, K. Chem. Lett. 1982, 679.

(13) Kartonozhkima, O. I.; Gabrakipov, V. Z.; Pak, A. M.; Chuvylkin,

N. D.; Sokol'skii, D. V. React. Kinet. Catal. Lett. 1982, 21, 85.
Selective semihydrogenation of an acetylenic function is a demanding task. Not only does the stereoselectivity ( $\mathrm{E} / \mathrm{Z}$ ratio) need to be controlled, but the hydrogenation of the resulting olefin to alkane must be suppressed as well. ${ }^{16-20} \mathrm{~F}$ or a long time, Lindlar's catalyst, 21,22 leaddoped palladium-on-calcium carbonate in combination with quinoline, has been used with varying success. ${ }^{23-28}$ Addition of various activators appeared to enhance the selectivity. The selectivity of supported palladium catalysts has been increased by addition of carbon monoxide,

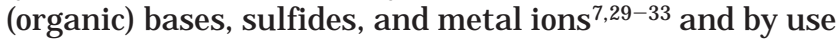
of other supports, such as sepiolite and pumice. ${ }^{34,35}$

(14) Rajaram, J.; Narula, A. P. S.; Chawla, H. P. S.; Dev, S. Tetrahedron 1983, 39, 2315.

(15) Ho, T. L.; Lin, S. H. Synth. Commun. 1987, 17, 969

(16) Augustine, R. L. Heterogeneous Catalysis for the Synthetic Chemist; Marcel Dekker: New York, 1995.

(17) Crombie, L. J . Chem. Soc. 1952, 6, 101.

(18) Raphael R. A. Acetylenes in Organic Synthesis; Academic Press: New York, 1955; $p 56$.

(19) Burwell, R. L. Chem. Rev. 1957, 57, 895. 180

(20) Figueras, F.; Gómez, R.; Primet, M. Adv. Chem. Ser. 1973, 121,

(21) Lindlar, H. Helv. Chim. Acta 1952, 34, 446

(22) Lindlar, H.; Dubuis, R. Org. Syn. 1966, 46, 89.

(23) Inhoffen, H. H.; Von der Bey, G. Liebigs Ann. Chem. 1953, 583, 100.

(24) Mildner, P.; Weedon, BCL. J . Chem. Soc. 1953, 3294.

(25) Crombie, L. J . Chem. Soc. 1955, 3510.

(26) Loev, B.; Dawson, C. R. J . Org. Chem. 1959, 24, 980.

(27) Shishido, K.; Kurozomi, S.; Utimoto, K. J . Org. Chem. 1969, 34, 2661.

(28) Büchi, G.; Egger, B. J . Org. Chem. 1971, 36, 2021.

(29) Bond, G. C.; Dowden, D. A.; McKenzie, N. Trans. Faraday Soc. $1958,1537$.

(30) Fukuda, T.; Kusama, T. Bull. Chem. Soc. J pn. 1958, 31, 339 (31) McQuillin, F.J .; Ord, W. O.; Simpson, P. L. J . Chem. Soc. 1963, 5996

(32) Freifel der, M. Practical Catalytic Hydrogenation; Wiley-I nterscience: New York, 1971; p 99.

(33) Petro, J . In Contact Catalysis; Szabo, Z. G., Kallo, D., Eds.; Elsevier: Amsterdam, 1976; Vol. II, p 65.

(34) Aramendía, M. A.; Borau, V.; J iménec, C.; Marinas, J. M.; Sempere, M. E.; Urbano, F. J . Appl. Catal. 1990, 63, 375.

(35) Duca, D.; Liotta, L. F.; Deganello, G. J . Catal. 1995, 154, 69. 
Furthermore, palladium can be alloyed with copper, silver, platinum, and other metals to improve the selectivity. ${ }^{29,36-40}$ Recently, N osova et al ${ }^{41}$ reported on a bimetallic palladium-copper catalyst supported on alumina with which they were able to selectively semihydrogenate vinyl acetylene to butadiene in the gas-phase at low temperatures. Analogous results were published by another group. ${ }^{42}$

In contrast to gas-phase reactions, which are less sensitive to mass-transport limitations, liquid-phase reactions with supported catalysts tend to exhibit masstransport limitation due to the smaller diffusion coefficients in liquids. ${ }^{43}$ The support bodies for liquid-phase catalysts should have dimensions within the range of 3 to about $50 \mu \mathrm{m}$, not only to avoid transport limitations, but also to minimize problems with separation of the catalyst from the liquid. With support bodies of this size, the high-temperature hydrogen reduction of the metal salt precursor(s) to catalysts may present problems such as blow-out of the solid or channelling. Furthermore, such reduction does not guarantee the formation of alloy phases. ${ }^{44,45}$ Therefore, catalysts for liquid-phase reactions are mainly restricted to supported metals of which the salts are readily reduced at ambient temperature or to unsupported metals in highly disperse form like Raney metals. To avoid high-temperature reduction, it is also possible to prepare metal particles by decomposing organometallic complexes, chemically, thermally, or by reduction. ${ }^{46-53}$ For example, Cocco et al. prepared supported palladium-platinum alloys by reaction of a mixture of palladium and platinum allyl compounds in pentane with the surface hydroxyl groups of the support, followed by reduction with hydrogen. ${ }^{54}$

We here report a fast and facile preparation of supported bimetal lic catalysts, including those of less noble metals, which is based on the reduction of organometallic compounds on the surface of a support in solution at room temperature (rt). This method circumvents high-temperature activation, and the catalyst can be used directly after the deposition of the metal particles. On the basis of our earlier work, 55,56 silica-supported bimetallic palladium-copper catalysts have been prepared by reaction

(36) Carturan, G.; Cocco G. J . Mol. Catal. 1984, 26, 375.

(37) Leviness, S.; Nair, V.; Weiss, A. H.J . Mol. Catal. 1984, 25, 131.

(38) Aduriz, R. H.; Bodnariuk, P.; Coq, B.; Figueras, F. J . Catal. 1991, 129, 47.

(39) Frevel, L. K.; Kresley, L. J . U.S. Patent 2802 889, 1957.

(40) Boitiaux, J. P.; Cosyns, J. E.P. Patent 0089 252, 1983.

(41) Nosova, L. V.; Zaikovskii, V. I.; Kalkinkin, A. V.; Talzi, E. P.; Paukstitis, E. A.; Ryndin, Xu. A. Kinet. Catal. 1995, 36, 328.

(42) Renouprez, A. J.; Lebas, K.; Bergeret, G.; Rousset, J . L. Delichère, P. Stud. Surf. Sci. Catal. 1996, 101, 1105.

(43) Cussler, E. L. Diffusion: Mass transfer in fluid systems; Cambridge University Press: Cambridge, 1984; Chapter 2 and 9.

(44) Ruiz-Vizcaya, M. E.; Novaro, O.; Ferreira, J . M.; Gomez, R. J . Catal. 1978, 51, 108.

(45) Grill, M.; Gonzales, R. D. J . Catal. 1980, 64, 487.

(46) Cymbaluk, T. H. U.S. Patent 4659 687, 1987.

(47) Schwartz, J. J. Mol. Catal. 1992, 72, 373.

(48) Didillon, B.; Candy, J . P.; Le Peletier, F.; Ferretti, O. A.; Basset,

J . M. Stud. Surf. Sci. Catal. 1993, 78, 147.

(49) Usui, K.; Nishiyama, Y.; Arai, M. J . Chem. Soc., Chem Commun. 1993, 1853.

(50) Nogin, Y. N. Catal. Lett. 1994, 23, 79.

(51) Nédez, C.; Lefebvre, F.; Choplin, A.; Niccolai, G. P.; Basset, J .

M.: Benazzi, E. J. Am. Chem. Soc. 1994, 116, 8638.

(52) Matsuda, T.; Shizuta, M.; Yoshizawa, J .; Kikuchi, E. Appl. Catal. 1995, 125, 293.

(53) Abis, L.; Dell'Amico, D.: Calderazzo, F .; Caminiti, R.; Garbassi, F.; I anelli, S.; Pelizzi, G.; Robino, P.; Tomei, A. J . Mol. Catal. 1996, 108, L113.

(54) Cocco, G.; Carturan, G.; Enzo, S.; Schiffini, L. J . Catal. 1984 $85,405$.

\section{Scheme 1. Preparation of Lithium $\mathrm{Di}\left(4-\right.$ tolyl)cuprate and $\mathrm{PdCu} / \mathrm{SiO}_{2}$}
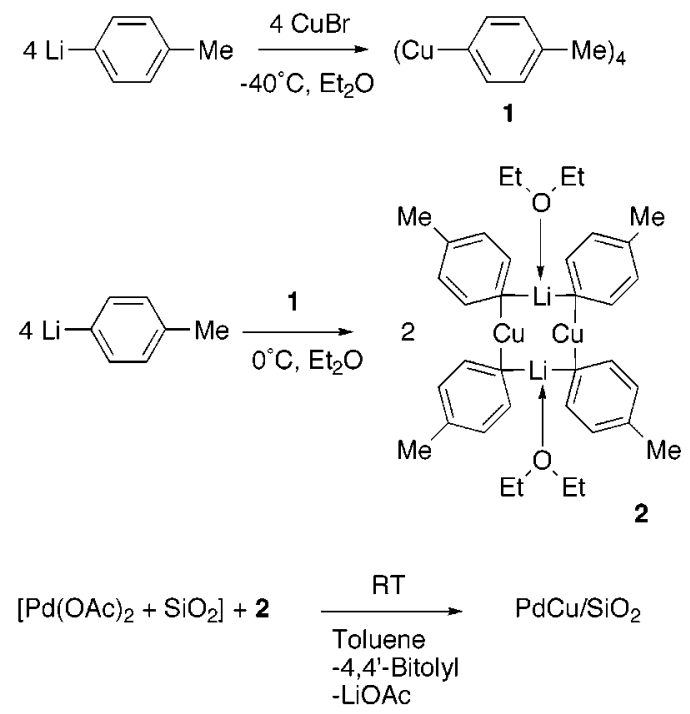

of a lithium cuprate and a palladium(II) salt to give a bimetallic-organometallic intermediate, in which copper and palladium are linked by bridging organic ligands. Subsequent decomposition of this intermediate gives an $\mathrm{Pd}-\mathrm{Cu}$ alloy that is deposited. This deposition proceeds at $\mathrm{rt}$ and does not require heating. The atomic mixing of the two metals present in the precursor prior to deposition leads to a homogeneous combination of the metals in the metallic phase, and consequently to more active and/or selective catalysts.

The $\mathrm{PdCu} / \mathrm{SiO}_{2}$ catalysts prepared according to an optimized protocol have been used in the liquid-phase semihydrogenation of several multifunctionalized acetylenes and propargylic alcohols.

\section{Results and Discussion}

Catalyst Preparation. On the basis of earlier work, ${ }^{55,56}$ silica-supported palladium-copper catalysts were prepared using lithium di(4-tolyl)cuprate (see Scheme 1). Addition of a toluene solution of the cuprate $\mathbf{2}$ to a solution of palladium(II) acetate in toluene at rt most probably leads to the in situ formation of a thermally unstable organocopper-palladium complex in which the lithium atoms of $\mathbf{2}$ have been replaced by the more electronegative precious metal. Evidence for the formation of such a thermally labile mixed metal intermediate can be found in the isolation and characterization of copper bis([(dimethylamino)methyl] ${ }^{2}$ henyl)aurate, $\left[\mathrm{Au}_{2^{-}}\right.$ $\left.\mathrm{Cu}_{2}\left(\mathrm{C}_{6} \mathrm{H}_{4} \mathrm{CH}_{2} \mathrm{NMe}_{2}-2\right)_{4}\right]$, prepared by the transmetalation of the lithium aurate with copper(I) bromide. ${ }^{66}$ The

(55) Cohen, M. S.; Noltes, J . G.; van Koten, G. U.S. Patent 4152 303, 1979.

(56) Cohen, M. S.; Noltes, J . G.; van Koten, G. U.S. Patent 4222 898, 1980.

(57) J ohnson, E. L.; McEwen, J. J . Am. Chem. Soc. 1926, 48, 475.

(58) Smith, L. I.; Hoehn, H. H. J. Am. Chem. Soc. 1941, 63, 1176.

(59) Pittman, C.; Olah, G. J . Am. Chem. Soc. 1965, 87, 5632.

(60) Brandsma, L.; Verkruijsse, H. D. Synthesis of Acetylenes, Allenes and Cumulenes; Elsevier Scientific Publishing Company: Amsterdam, 1981.

(61) Brandsma, L.; Verkruijsse, H. D. Preparative Acetylenic Chemistry, 2nd ed.; Elsevier: Amsterdam, 1988.

(62) Fleming, I.; Takai, K.; Thomas, A. P. J . Chem. Soc., Perkin Trans. 1 1987, 2269

(63) Steenwinkel, P.; J ames, S. L.; Grove, D. M.; Veldman, N.; Spek, A. L.; van Koten, G. Chem. Eur. J . 1996, 2, 1440. 

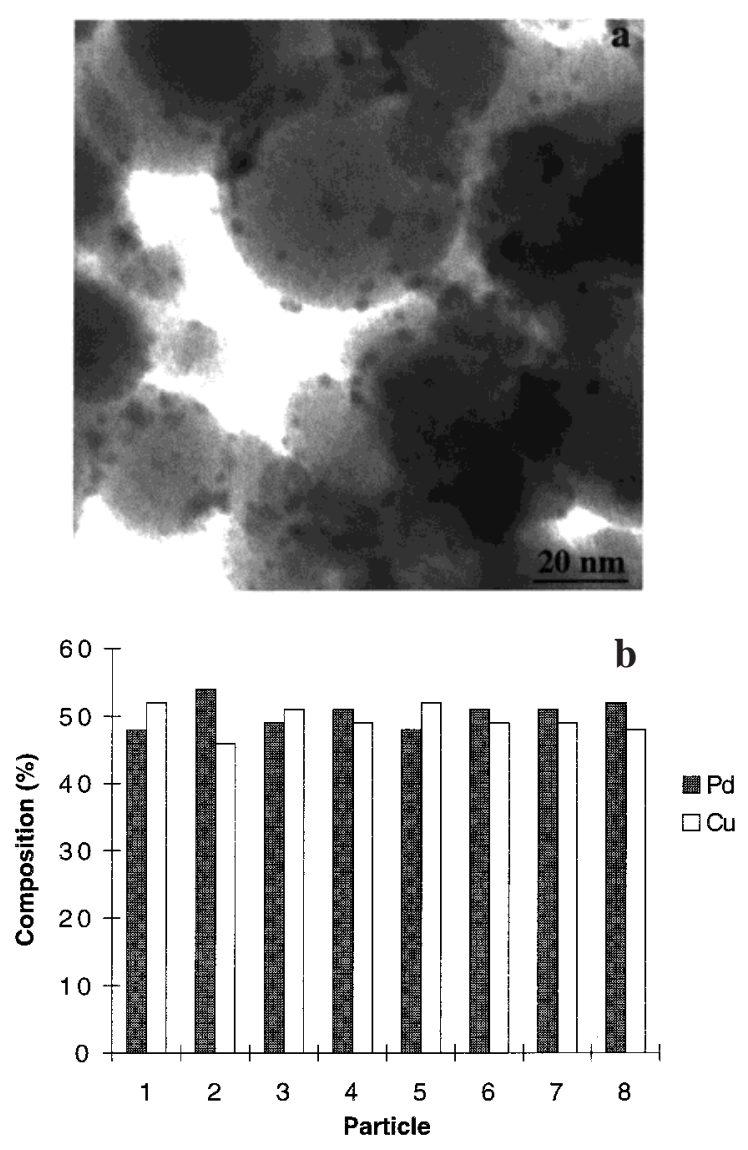

Figure 1. (a) TEM image of $\mathrm{PdCu} / \mathrm{SiO}_{2}(\mathrm{Pd} / \mathrm{Cu}=1: 1$, atomic ratio). (b) Elemental composition (atomic \%) of particles of $\mathrm{PdCu} / \mathrm{SiO}_{2}(\mathrm{Pd} / \mathrm{Cu}=1: 1$ atomic ratio).

formation of this copper aurate clearly demonstrates the mixing of the two metals on an atomic scale. Supported bimetallic palladium-copper particles are formed after reductive elimination of the organic group from the unstable organometallic palladium(II)-copper(I) intermediate. When the reaction is performed in the presence of suspended silica powder, this intermediate is deposited onto the support.

After the deposition of the bimetallic particles has been completed, hydrogen is added to the system to ensure complete reduction. Following this protocol, salt-free palladium-copper catalysts $\mathrm{Pd}(4 \mathrm{wt} \%) \mathrm{Cu}(2.4 \mathrm{wt} \%) / \mathrm{SiO}_{2}$ (I) and $\mathrm{Pd}\left(4\right.$ wt \%)Cu(4.8 wt \%)/ $\mathrm{SiO}_{2}$ (II) with atomic metal ratios $\mathrm{Pd} / \mathrm{Cu}$ of $1: 1$ and $1: 2$, respectively, were prepared. The presence of both palladium and copper at the surface of the catalyst has been established by X-ray photoel ectron spectroscopy (XPS). In Figures 1a and 2a, transmission electron microscopy (TEM) images of the two catalysts are shown. The supported metal particles (dark spots) are well dispersed over the larger silica spheres and have a size ranging between 2 and $4 \mathrm{~nm}$. Energy Dispersive X-ray Analysis (EDAX) (see Figures $1 \mathrm{~b}$ and $2 \mathrm{~b}$ ) revealed a metal composition equal to the amounts of metal precursors added. No pure palladium or copper particles have been detected, which indicates that the two metals are well-mixed. This is most likely a result of the fact that not only the two metals in the

(64) van Koten, G.; J astrzebski, J . T. B. H.; Noltes, J . G. J . Org. Chem. 1977, 42, 2047.

(65) van Koten, G. J . Organomet. Chem. 1977, 140, C23.

(66) van Koten, G.; Noltes, J . G. J . Organomet. Chem. 1974, 82, C53.
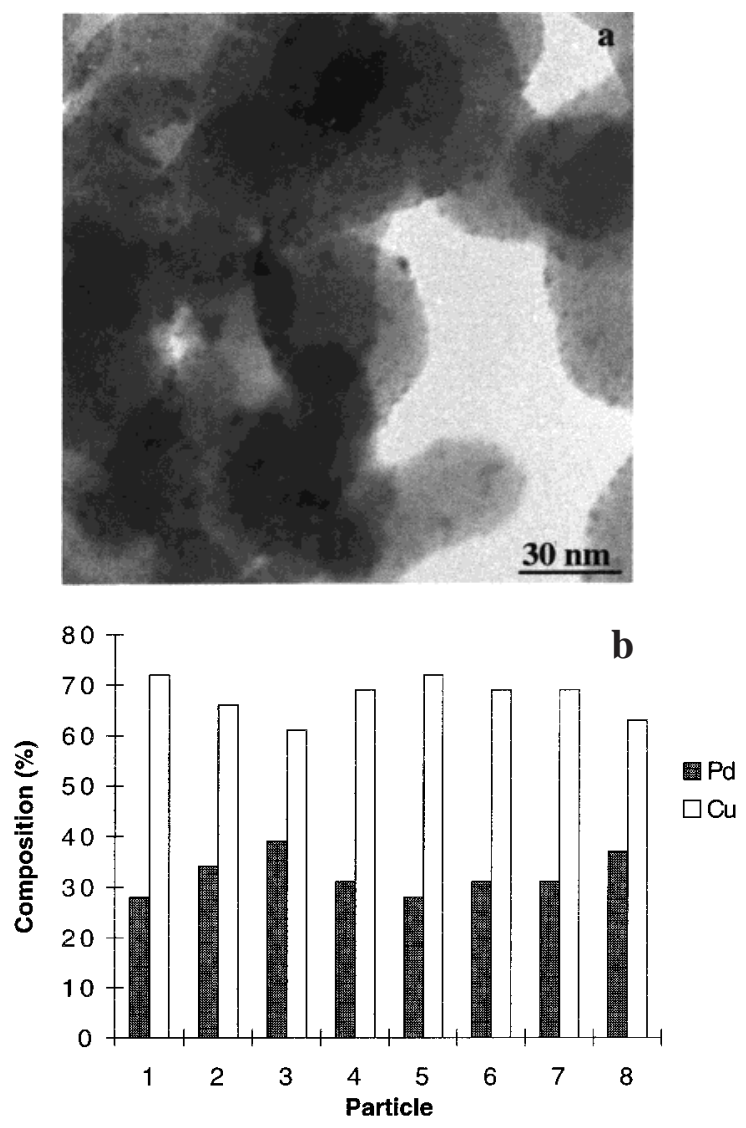

Figure 2. (a) TEM image of $\mathrm{PdCu} / \mathrm{SiO}_{2}(\mathrm{Pd} / \mathrm{Cu}=1: 2$ atomic ratio). (b) Elemental composition (atomic \%) of particles of $\mathrm{PdCu} / \mathrm{SiO}_{2}(\mathrm{Pd} / \mathrm{Cu}=1: 2$ atomic ratio).

Table 1. Fit Parameters ( $\Delta \mathrm{k}: 3.5-14.5 \AA^{-1}, \Delta R: 1-3 \AA$ ) for $\mathrm{Pd}(1.92$ wt $\%) \mathrm{Cu}(1.75$ wt $\%) / \mathrm{SiO}_{2}$ and $\mathrm{Pd}(1.95$ wt $\%) \mathrm{Cu}(3.10$ wt \%)/SiO 2

\begin{tabular}{cccccc}
\hline catalyst & scatterer & $\mathrm{N}$ & $\begin{array}{c}\mathrm{R} \\
(\AA)\end{array}$ & $\begin{array}{c}\Delta \sigma^{2} \\
\left(10^{-3} \AA^{2}\right)\end{array}$ & $\begin{array}{c}\Delta \mathrm{E}_{0} \\
(\mathrm{eV})\end{array}$ \\
\hline $\mathrm{Pd}(1.92$ wt \%)- & $\mathrm{Pd}$ & 4.1 & 2.69 & 18 & 0.67 \\
$\mathrm{Cu}(1.75$ wt \%)/SiO & & & \\
& $\mathrm{Cu}$ & 6.9 & 2.56 & 7.3 & 12 \\
$\mathrm{Pd}(1.95$ wt \%)- & $\mathrm{Pd}$ & 2.7 & 2.65 & 25 & -2.9 \\
$\mathrm{Cu}(3.10$ wt \%)/SiO & \\
& $\mathrm{Cu}$ & 8.2 & 2.57 & 6.1 & 3.6
\end{tabular}

organometallic precursor are linked by aryl ligands, i.e., are premixed on an atomic scale, but also that the reductive elimination to give the reduced metals occurs in an intramolecular way. As this process as well as the subsequent treatment with hydrogen occurs at rt, sintering and segregation do not occur.

The silica-supported palladium-copper catalysts were also characterized using extended X-ray absorption fine structure spectroscopy (EXAFS). Two samples with different $\mathrm{Pd} / \mathrm{Cu}$ atomic ratios were characterized: $\mathrm{Pd} / \mathrm{Cu}=$ $1: 1.5$ and $1: 2.7$. The fit parameters of the calculated spectra are given in Table 1. The calculated coordination numbers $(\mathrm{N})$ of the $\mathrm{Pd}-\mathrm{Pd}$ and $\mathrm{Pd}-\mathrm{Cu}$ coordination are proportional to the amount of palladium and copper present in the sample. For both samples, the total coordination number around palladium is 11 , which is indicative for an average particle size of about $40 \AA$. Within the limits of accuracy, this particle size is in agreement with the metal particle size as observed with TEM. The Pd-Pd distances differ from that present in bulk samples $(2.74 \AA)$. This difference is caused by the 
fact that the metal particles are small and that the electronic structure is changed by the presence of copper. The data obtained by EXAFS measurements do not provide information about the presence or absence of surface enrichment by palladium or copper. However, it is clear that palladium and copper are well-mixed within the particle. When the results of the EXAFS measurements and the results of the semihydrogenation tests (vide infra) are combined, it can be concluded that the palladium present at the surface is diluted by copper resulting in small ensembles. The EXAFS data presented here do not exclude that the surface of the metal particles is to some extent enriched by copper or palladium.

Catalytic Hydrogenations. We tested the catalytic performance of the silica-supported palladium-copper catalysts I and II in the hydrogenation of several functi onal ized acetyl enes. We choose 3-methyl-1-pentyn-3-ol (eq 1 ) as a test substrate, because of its fast rate of conversion and the usefulness of converting a propargylic alcohol into its semihydrogenated product. $67-69$ Also, (semi)hydrogenation of propargylic alcohols is generally not very selective. ${ }^{16}$

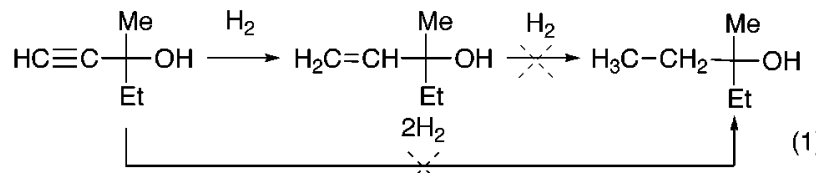

All reduction reactions were performed in a $250 \mathrm{~mL}$ reactor with three baffles equipped with a mechanical stirrer. To check whether diffusion-limited processes occurred, we varied the stirring rates, the amounts of substrate, and the amounts of catalyst. Variation of the stirring rate showed that the rate of the reaction remains constant above $2000 \mathrm{rpm}$. While at low substrate concentrations ( $2.5 \mathrm{mmol}$ substrate/ $125 \mathrm{~mL}$ of ethanol) the rate depends on the substrate concentration, it remains constant for substrate concentrations larger than $5 \mathrm{mmol}$ per $125 \mathrm{~mL}$ of ethanol. This may be explained by assuming that at low substrate concentrations this is the limiting factor while at higher concentrations the rate is limited by hydrogen diffusion from the bulk of the solution to the catalyst surface (under the reaction conditions the solubility of the hydrogen is at least 1 order of magnitude smaller than that of the substrate).

Comparison of the Performances of Catalyst I, $\operatorname{Pd}\left(4\right.$ wt \%)Cu(2.4 wt \%)/SiO ${ }_{2}$, and Catalyst II, $\mathrm{Pd}(4$ wt \%)Cu(4.8 wt \%)/SiO ${ }_{2}$. Comparison of the catalytic performances of catalyst I and II when used in the hydrogenation of $12.5 \mathrm{mmol}$ of the test substrate indicates that the selectivity of the catalysts toward the formation of the semihydrogenated product, 3-methyl-1penten-3-ol, is virtually identical (see Figure 3a,b).The lower activity of catalyst II (about $50 \%$ of the activity of catalyst I) is probably due to the fact that palladium is more diluted with copper and less palladium sites are exposed. Because of the small differences in selectivity between both catalysts, we have further studied the properties and performances of catalyst I only.

Performance of Catalyst I, Pd(4 wt \%)Cu(2.4 wt $\%) / \mathbf{S i O}_{2}$. When catalyst I was used in the hydrogenation

(67) Sokol'skii, D. V.; Omarkulov, T. O.; Zhubanova, L. K.; Mukataev, Z. H.; Popova, N. I. Zh. Org. Khim. 1987, 23, 1430.

(68) Alper, H. Eur. Patent 338 730, 1988.

(69) El Ali, B.; Alper, H. J . Org. Chem. 1991, 56, 5357.
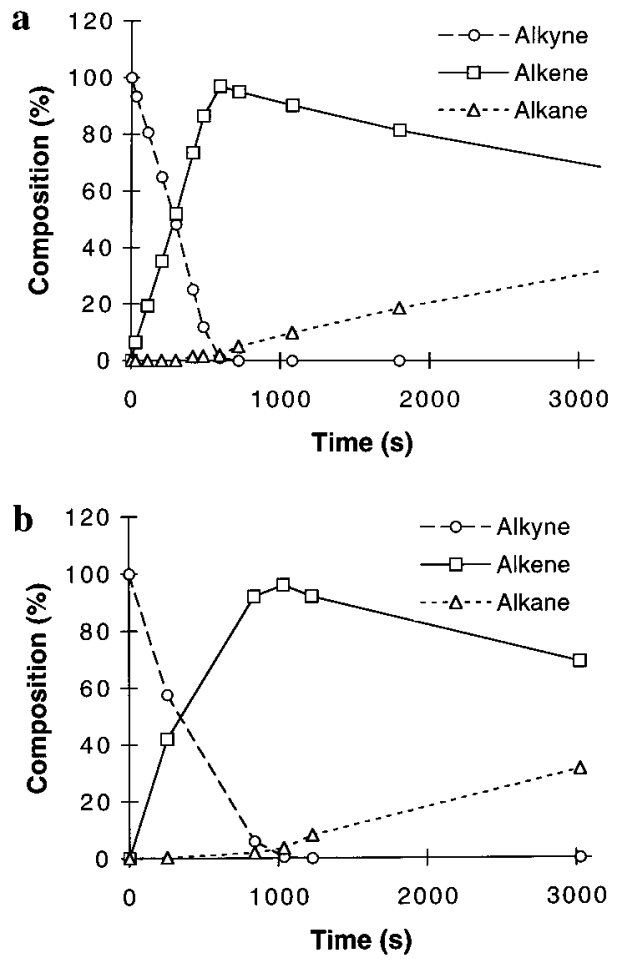

Figure 3. (a) Hydrogenation of 3-methyl-1-pentyn-3-ol (12.5 $\mathrm{mmol}$ ) using Catalyst I (0.030 g). (b) Hydrogenation of 3-methyl-1-pentyn-3-ol (12.5 mmol) using catalyst II (0.030 g).
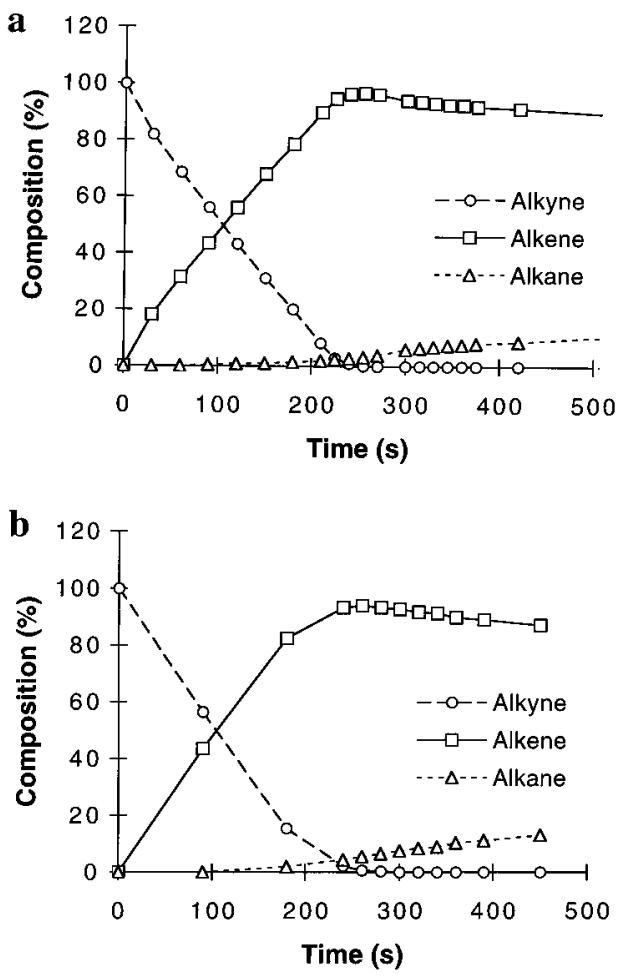

Figure 4. (a) Hydrogenation of 3-methyl-1-pentyn-3-ol (5 mmol) using catalyst I $(0.035 \mathrm{~g})$. (b) Hydrogenation of 3-methyl-1-pentyn-3-ol (5 mmol) using a Lindlar catalyst (5 wt \% Pd, 3 wt \% Pb, $0.028 \mathrm{~g})$.

of 3-methyl-1-pentyn-3-ol, within a few minutes the alkyne was completely reduced to alkene (97\%), while only $3 \%$ of alkane was formed by over-reduction (Figure 4a). The performance of catalyst I was compared with that of a palladium catalyst with very small $(<1 \mathrm{~nm})$ 
metal particles supported on the same silica support (to avoid differences in transport properties). This catalyst was prepared by ion exchange with the silanol groups of the silica support at $\mathrm{pH} 9$ using an aqueous solution of tetra-amine palladium(II) nitrate followed by oxidation and reduction. Using the same conditions as with catalyst I, the alkyne was converted to alkene with a selectivity of $80 \%$. Apparently, atomic mixing of copper with the catalytically active pal ladium does increase the selectivity in the semihydrogenation of propargylic al cohols. Wealso compared catalyst I with a standard Lindlar catalyst under the same conditions using the same weight of palladium. The selectivity of catalyst I toward the semihydrogenated product is measurably better (97\%) than that of the Lindlar catalyst (94\%). Also, the rate of overhydrogenation $\left(r_{0}\right)$ to the alkane is lower for I (see Figure 4a,b).

With catalyst weights of 30,50 , and $70 \mathrm{mg}$ the specific rates of the semihydrogenation $\left(\mathrm{mmol} \cdot \mathrm{min}^{-1} \cdot \mathrm{mg} \mathrm{Pd}^{-1}\right)$ agreed within about $5 \%$. Therefore, in this range transport limitations are minimal and the reaction runs in the so-called kinetic regime. With low amounts of catalyst (16 and $8 \mathrm{mg}$ ), it was found that the activity per $\mathrm{mg}$ of catalyst decreases to $60 \%$ and $4 \%$, respectively. A possible explanation is that such small amounts of catalyst may be poisoned by trace impurities present in the solvent used.

In conclusion, the catalytic hydrogenations should be performed using at least $5 \mathrm{mmol}$ of substrate and $35 \mathrm{mg}$ of catalyst $\left(1.4 \times 10^{-2} \mathrm{mmol}\right.$ palladium and $1.4 \times 10^{-2}$ mmol copper), $125 \mathrm{~mL}$ of ethanol with $2000 \mathrm{rpm}$ stirring rate, and atmospheric hydrogen pressure. Using this standard protocol, the alkyne conversion plot is linear up to a few percent of residual alkyne. This confirms that, as stated above, under these conditions the availability of hydrogen is rate-determining.

The catalyst stability in the reduction of 3-methyl-1pentyn-3-ol and of diphenylacetylene was tested by successive reduction of portions of $5 \mathrm{mmol}$ of substrate using the same batch of catalyst. The new portions of alkyne were added directly after completion of the semi hydrogenation step. For 3-methyl-1-pentyn-3-ol the catalyst activity remained constant up to the third successive reduction. After the fourth reduction the activity decreased to $70 \%$ and after the fifth to $50 \%$. For diphenylacetylene the activity decreased by $50 \%$ after each reduction. The constancy of the catalyst activity during the first three additions may be explained by assuming that in that regime the reaction rate is still limited by hydrogen diffusion and that catalyst activity becomes the limiting factor only if it has decreased sufficiently. To check if the loss of activity was caused by competitive adsorption of the alkene, the concentration of which rises after each reduction, we reused the catalyst after a workup which consisted of washing with ethanol and drying in vacuo. A small variation in catalyst activity was observed, but the variations were not proportional to the number of hydrogenation runs. Apparently, the catalyst is quite stable in the liquid-phase reductions of alkynes. It could be stored under nitrogen for several months without loss of activity and selectivity.

Effect of Catalyst Preparation on the Performance of Catalyst I. The mode of addition of the palladium salt solution and the organocopper solution appeared to be very important for the performance of the catalyst. Under optimal conditions the catalyst selectivity

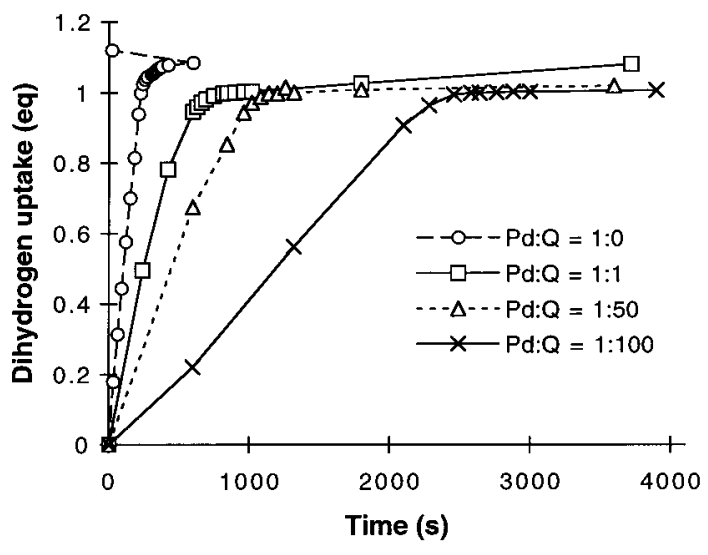

Figure 5. Effect of quinoline addition on the rate of hydrogen uptake in the hydrogenation of 3-methyl-1-pentyn-3-ol.

toward 3-methyl-1-penten-3-ol was $97 \%$. The rate of semihydrogenation $\left(r_{s}\right)$ was high, viz., $0.81 \mathrm{mmol} \cdot \mathrm{min}^{-1} \cdot \mathrm{mg}$ $\mathrm{Pd}^{-1}$ compared to that of the consecutive reduction $\left(r_{0}\right)$, viz. $0.026 \mathrm{mmol} \cdot \mathrm{min}^{-1} \cdot \mathrm{mg} \mathrm{Pd}^{-1}$, which corresponds with a ratio of $r_{s} / r_{0}$ of 31 . This is better than found for the Lindlar catalyst (without quinoline addition) (96\% selectivity, $0.8 \mathrm{mmol} \cdot \mathrm{min}^{-1} \cdot \mathrm{mg} \mathrm{Pd}^{-1}, \mathrm{r}_{\mathrm{s}} / \mathrm{r}_{\mathrm{o}}=13$ ).

In the optimized preparation procedure the palladium salt is added via a peristaltic pump at least $3 \mathrm{~h}$ prior to the addition of the organocopper solution. This ensures uniform, homogeneous mixing of the palladium salt solution and the support material. Reaction of the resulting well-mixed suspension with a freshly prepared light yellow solution of the lithium cuprate, introduced again via a peristaltic pump, then leads to the formation of small bimetallic particles of high activity and sel ectivity.

Lithium di(4-tolyl)cuprate is very sensitive to light, oxygen and water. Reaction with traces of oxygen or water immediately results in the formation of metallic copper particles that causes the light yellow organocopper solution to assume a green color. This metallic copper will not be involved in the deposition reaction with the palladium compound. When a palladium(II) acetate/silica suspension is reacted with such a green lithium di(4tolyl)cuprate solution, part of the palladium(II) acetate will remain before exposure to hydrogen. TEM-EDAX observations showed the presence of relatively large palladium-rich particles. This results in a quite active catalyst (part of the palladium is not alloyed or covered with copper) of a lower selectivity (96\%) and significantly lower $r_{s} / r_{0}$, viz., 6 . During all experiments mentioned here catalyst batches were used that had an activity varying by no more than $10 \%$ from the mean level of 0.8 $\mathrm{mmol} \cdot \mathrm{min}^{-1} \cdot \mathrm{mg} \mathrm{Pd}^{-1}$ and had an $\mathrm{r}_{\mathrm{s}} / \mathrm{r}_{0}$ ratio of $30 \pm 5$.

Effect of Quinoline Addition, Air Exposure, and Potassium Hydroxide Addition on the Performance of Catalyst I. Since it is well-known that addition of quinoline has a beneficial influence on the selectivity of the Lindlar catalyst, 2,21,22 we investigated the effect of quinoline on catalyst $\mathbf{I}$. Addition of 1 equiv of quinoline to the reaction mixture resulted in a decrease of the rate of overhydrogenation $r_{0}$. Increasing the palladium/quinoline ratio from $1: 1$ to $1: 50$ and 1:100, respectively, brought about a larger decrease of $r_{0}$ compared to the decrease of $r_{s}$ (see Figure 5), while the sel ectivity further improved from $97 \%$ to $99 \%$.

The effect of addition of quinoline to our palladiumcopper catal yst I was compared with that found with the 

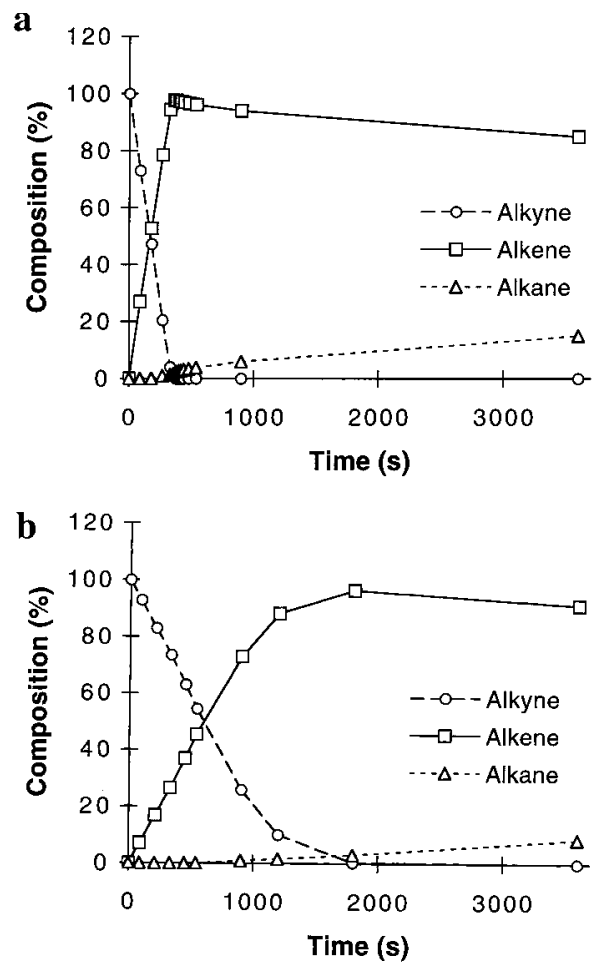

Figure 6. (a) Hydrogenation of 3-methyl-1-pentyn-3-ol (5 $\mathrm{mmol})$ using catalyst I $(0.035 \mathrm{~g})$ in the presence of quinoline (25 equiv). (b) Hydrogenation of 3-methyl-1-pentyn-3-ol (5 mmol) using a Lindlar catalyst (5 wt \% Pd, 3 wt \% Pb, 0.028 $\mathrm{g}$ ) in the presence of quinoline ( 25 equiv).

Lindlar catalyst. The $r_{s} / r_{0}$ observed for I changed from 31 (no quinoline present) to 75 , when 25 equiv of quinoline was present. The addition of 25 equiv of quinoline to the Lindlar catalyst resulted in an increase of the selectivity (96\%), and a decrease of the $r_{0}$ (see Figure $6 a, b)$. However, addition of quinoline to the Lindlar catalyst brought about a drop in $r_{s}$ by a factor of 6 (this drop is only a factor 2 for catalyst I) while the drop in $r_{0}$ is comparable with both catalyst systems. The higher $r_{s} / r_{0}$ ratio found for catalyst I (75) as compared to that found for the Lindlar catalyst (27) under the same conditions, indicates a far higher selectivity for semihydrogenation of catalyst I, which facilitates the formation and isolation of the desired alkene. Quinoline addition in reductions of other substrates gave similar results. In al most all cases the selectivity toward the alkene formation was raised by a few percent and the rate of overhydrogenation was decreased.

Influence of Oxygen. In all our catalytic runs, the palladium-copper catalyst was kept under a nitrogen atmosphere because the hydrogenation rate decreases when the catalyst is exposed to air. Exposing the catalyst to an atmosphere of hydrogen ( $1 \mathrm{~atm}$ at $\mathrm{rt}$ ) prior to catalysis did not restore the initial activity of the airexposed catalyst (see Figure 7). It is inter esting to note, however, that the $r_{0}$ is affected more than $r_{s}\left(r_{s} / r_{0}=68\right)$, resulting in the same type of selectivity vs activity as we found with the catalysts upon addition of quinoline. The drop in activity and the increase in selectivity may be caused by copper segregation to the surface of the bimetallic particles, which can lead to smaller palladium ensembles (diluting effect) and/or because a (greater) part of the aselective palladium sites is being covered. Both phenomena can increase the selectivity toward the alk-

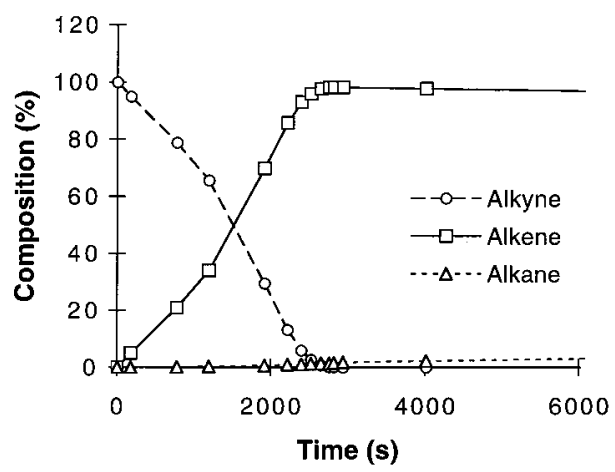

Figure 7. Hydrogenation of 3-methyl-1-pentyn-3-ol ( $5 \mathrm{mmol}$ ) using catalyst I $(0.035 \mathrm{~g})$ after exposure of the catalyst to air.

ene. ${ }^{36,39,70}$ Another explanation may be that oxidation of the copper to a higher oxidation state is responsible for the high selectivity in the semihydrogenation, whereas the completely reduced alloy particles are less selective. For example, it has been demonstrated that metal ions (e.g., $\mathrm{Pb}^{2+}$ ) present in palladium particles do not get reduced (under hydrogenation conditions) to the zerovalent state. The nonreducible metal ions are suggested to interact with their d-electrons forming intermetallic bonds at the pal ladium surface thus causing obstructive occupation of the catalyst surface. ${ }^{71}$ The selectivity increases due to exposure to oxygen can be of great synthetic use in isolating the desired alkene.

The uptake of hydrogen during the semihydrogenation of 3-methyl-1-pentyn-3-ol also almost completely ceased after uptake of 1 equival ent, when 1-2 equiv of potassium hydroxide (as ethanol solution) were added to the reaction mixture. The large influence of potassium hydroxide on the selectivity of semihydrogenation catalysts has been reported earlier. ${ }^{72,73}$ Besides the extremely high $r_{s} / r_{0}$ ratio (330), the yield of the alkene is also high (99.5\%).

Influence of the Solvent. The type of solvent used in hydrogenation reactions can have a large influence on the activity and selectivity. ${ }^{74-76}$ When the solvent is varied in the semihydrogenation of 3-methyl-1-pentyn3-ol using the silica-supported palladium-copper catalyst, all reactions remain pseudo first order with respect to hydrogen independent of the solvent used. The supply of hydrogen is therefore still the rate-determinating step. The semihydrogenation is faster in methanol than in ethanol (see Figure 8a). A higher rate of conversion was al so found when a small amount of water (3\%) was added to the reaction mixture, when ethanol was employed as a solvent.

When pure and dry toluene or pentane was used, the semi hydrogenation proceeded very slowly. A part from the lower solubility of hydrogen in these solvents, this is most probably due to clustering of the catalyst particles (see Figure 8b).

An increase of the polarity of the solvent apparently raises the rate of semihydrogenation. The hydrophilic

(70) Sárkány, A.; Weiss, A. H.; Guczi, L. J . Catal. 1986, 98, 550.

(71) Maxted, E. B. J . Chem. Soc. 1949, 1987.

(72) Tedeschi, R. J. J . Org. Chem. 1962, 27, 2398.

(73) Tedeschi, R. J .; Clark, G. S., J R. J . Org. Chem. 1962, 27, 4323

(74) Koopman, P. G. J .; Buurmans, H. M. A.; Kieboom, A. P. M. van Bekkum, H. Recl. Trav. Chim. Pays-Bas 1981, 100, 156.

(75) Wauquier, J . P.; J ungers, J . C. Bull. Soc. Chim. Fr. 1957, 1280

(76) Cerveny, L.; Prochazha, A.; Zenezny, M.; Ruzicka, V. Collect. Czech. Chem. Commun. 1979, 44, 2328. 

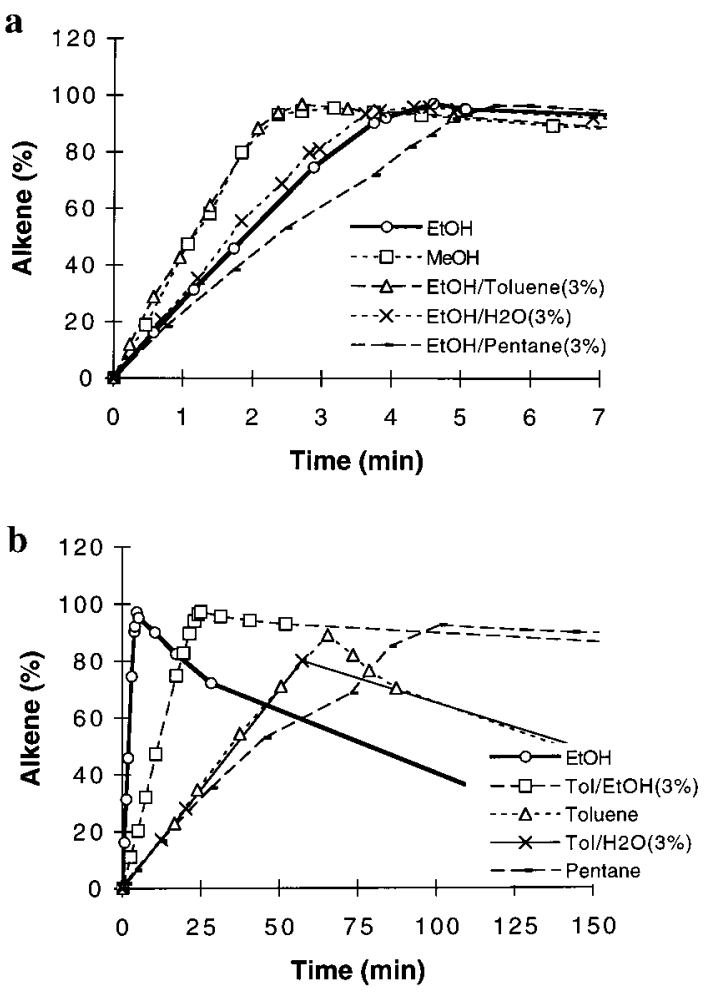

Figure 8. (a) Solvent effects on the hydrogenation of 3-methyl-1-pentyn-3-ol $(5 \mathrm{mmol})$ using catalyst I $(0.030 \mathrm{~g})$. (b) Solvent effects on the hydrogenation of 3-methyl-1-pentyn-3-ol (5 $\mathrm{mmol})$ using catalyst I $(0.030 \mathrm{~g})$.

character of the silica support will promote dispersion of the catalyst in a more polar medium, resulting in higher activity. The increase in the rate of conversion when methanol or the mixture of ethanol and water are used was similar for both the alkyne and the alkene. The ratio $r_{s} / r_{0}$ did not change significantly as compared to that obtained when pure ethanol was used. The selectivity toward the alkene was also not influenced by these types of solvent. When toluene was used, over-hydrogenation was much faster. The ratio $r_{s} / r_{0}$ is the smallest in toluene, $r_{0}$ being almost equal to $r_{s}$. Addition of only a small amount of ethanol to the toluene was sufficient to restore the favorable adsorption constants and, thus, to achieve a high $r_{s} / r_{0}$ value, which is even a factor of 1.5 higher than that found in pure ethanol. Both toluene and ethanol can be adsorbed on the catalyst and interact with the substrate. Change of solvent, especially the layer covering the catalyst bodies, ${ }^{74}$ can change the relative adsorption constant of the al kyne as compared to that of the alkene thus influencing the $r_{s} / r_{0}$ value. The substantial increase of the reaction rate cannot be ascribed to an increase in the amount of dissolved hydrogen, but may be caused by a better distribution of the catalyst in toluene/ethanol as compared to pure toluene. Addition of a small amount of pentane (3\%) to ethanol lowered the rate of the reaction, whereas addition of $3 \%$ of toluene to ethanol led to an unexpected rise in activity (the activity reached the level found in methanol) (see Figure 8a). Presumably the addition of small amounts of other liquids affects the dispersion of the catalyst bodies within the liquids. The effects on the dispersibility are difficult to predict.

Performance of Catalyst I in the Semihydrogenation of Functionalized Acetylenes. The perfor- mance of catalyst I was tested in the semihydrogenation of mono- and difunctionalized acetylenes containing a variety of functional groups (see Table 2).

Phenylacetylene was converted into styrene with 95\% selectivity, which is the same as found for a $\mathrm{CaCO}_{3-}$ supported palladium-lead alloy catalyst, which was reported to be more selective than the Lindlar catalyst. ${ }^{77}$

Changing the substituents $R$ and $R^{\prime}$ in monosubstituted propargylic alcohols ( $\left.\mathrm{HC} \equiv \mathrm{CCRR}^{\prime} \mathrm{OH}\right)$ does not affect the catalyst selectivity toward the alkenol substantially. However, for $R=R^{\prime}=M e$ and $R=M e, R^{\prime}=$ Et the hydrogen uptake after completion of the semihydrogenation step slowed significantly, while for propynol $\left(\mathrm{R}=\mathrm{R}^{\prime}=\mathrm{H}\right) \mathrm{r}_{\mathrm{s}} \approx \mathrm{r}_{\mathrm{o}}$. The rate of conversion of the latter substrate was also higher. 1-Ethynyl-1-cyd ohexanol could be semihydrogenated with a selectivity of $94 \%$. Hydrogenolysis of the propargylic alcohols and aldehyde or ketone formation was not detected in any of the semihydrogenations. To prevent loss of the acetoxy group in propargylic esters, usually the hydrochloric or ammonium salts are reduced. ${ }^{78,79}$ However, using our catalyst, the hydrogenation could be performed selectively in high yields without hydrogenolysis of the acetate.

Both internal and external al kynes such as 3-hexyne, 2-hexyne, 1-hexyne, and 2-pentyne were reduced at a higher rate than the propargylic al cohols. Especially the rate of conversion of the disubstituted 2-hexyne and 3-hexyne were strikingly high as compared to that found for the propargylic alcohols and 1-hexyne. This is in contrast with the observation that the monosubstituted alkyne 3-butyn-2-ol is converted slightly faster than the disubstituted alkyne 2-butyn-1-ol. A marked difference was also found in the rate of conversion of 2-pentyn-1-ol and 3-pentyn-2-ol. The influence of steric hindrance on the rate of conversion for this substrate couple is opposite to that of 3-butyn-2-ol, 2-methyl-3-butyn-2-ol, and the test substrate. However, the sel ectivity toward both the cisalkenols 2-penten-1-ol and 3-penten-2-ol was high.

The selectivity in the semihydrogenation of 3-hexyn1 -ol $(99 \%$, cis/trans $=99 / 1)$ to the enol in $97 \%$ yield can very well compete with the reported semihydrogenation of this substrate over palladium-on-barium sulfate. ${ }^{80}$ Semihydrogenation of 3-hexyn-1-ol over palladium-oncalcium carbonate was found to give only $89 \%$ selectivity. ${ }^{81}$

The long-carbon-chain substrates 2-dodecyn-1-ol and 2-undecyn-1-ol are hydrogenated at a low rate. For substrates of a similar structure the rate usually decreases with increasing molecular weight. This effect could explain the difference in conversion rate between 2-butyn-1-ol, 2-dodecyn-1-ol and 2-undecyn-1-ol.

When an amine function is present, the selectivity of the catalyst is very high with $99 \%$ of the alkene being formed. Most probably the amino group in the substrate has the same function as quinoline in the reactions discussed above. Not surprisingly, the presence of a sulfide substituent poisons the catalyst and hence no activity was found. In an attempt to hydrogenate a

(77) Sotczak, J .; Boleslawska, M.; Pawlowska, M.; Pakzewska, W Stud. Surf. Sci. Catal. 1988, 41, 197.

(78) Marszak, J .; Marszak-Fleury, A. C. R. Acad. Sci., Paris, Ser. C 1949, 1501.

(79) Marszak, J .; Marszak-Fleury, A. Bull. Soc. Chim. Fr. 1950, 17, 1305

(80) Takei, S. Chem. Ber. 1940, 73, 950.

(81) Sonheimer, F. J . Chem. Soc. 1950, 877. 
Table 2. Performance of Catalyst I (4 wt \% Pd, 2.4 wt \% Cu) in the Semihydrogenation of Different Substrates

\begin{tabular}{|c|c|c|c|c|c|}
\hline \multirow{2}{*}{$\begin{array}{r}\text { substrate } \\
\text { 3-methyl-1-pentyn-3-ol }\end{array}$} & \multicolumn{2}{|c|}{$\begin{array}{c}\text { alkene } \\
\text { max yield (\%) }\end{array}$} & \multirow[t]{2}{*}{ cis/trans } & \multirow{2}{*}{$\frac{\begin{array}{c}\mathrm{r}_{\mathrm{s}} \\
\left(\mathrm{mmol} \mathrm{min}^{-1} \cdot \mathrm{mgPd}^{-1}\right)\end{array}}{0.81}$} & \multirow{2}{*}{$\begin{array}{r}r_{s} / r_{0} \\
31\end{array}$} \\
\hline & 97 & $98^{a}$ & & & \\
\hline 3-butyn-2-ol & 95 & & & 2.1 & 1 \\
\hline 2-methyl-3-butyn-2-ol & 98 & & & 0.56 & 25 \\
\hline 2-butyn-1-ol & 99 & & $99 / 1$ & 1.7 & 180 \\
\hline 2-pentyn-1-ol & 99.5 & & $99 / 1$ & 0.50 & 280 \\
\hline 3-pentyn-2-ol & 99 & & $99 / 1$ & 5.0 & 85 \\
\hline 3-hexyn-1-ol & 99 & & $99 / 1$ & 1.4 & 1000 \\
\hline propargyl alcohol & 85 & & & 1.0 & 1 \\
\hline 1-ethynylcyclohexanol & 94 & $97^{a}$ & & 0.75 & 5 \\
\hline 3-acetyl-3-methyl-1-pentyne & 95 & & & 0.60 & 1000 \\
\hline 2-pentyne & 99.5 & & 99/1 & 1.7 & 40 \\
\hline 1-hexyne & 91 & & & 1.3 & 8 \\
\hline 2-hexyne & 97 & & $98 / 2$ & 4.9 & 100 \\
\hline 3-hexyne & 99.5 & & $99.5 / 0.5$ & 5.1 & 80 \\
\hline 2-dodecyn-1-ol & 100 & & $100 / 0$ & 0.11 & 30 \\
\hline 2-undecyn-1-ol & $100 / 0$ & & $100 / 0$ & 0.06 & 100 \\
\hline 2-butyne-1,4-diol & 99 & & $99 / 1$ & 0.33 & 25 \\
\hline phenylacetylene & 95 & $96^{a}$ & & 0.31 & 1 \\
\hline diphenylacetylene & 91 & $98^{a}$ & $96 / 4$ & 0.57 & 15 \\
\hline 1-phenyl-1-butyn-3-ol & 80 & $91^{a}$ & $98 / 2$ & 0.57 & 24 \\
\hline 1-phenyl-3-methyl-1-butyn-3-ol & 58 & $85^{b}$ & $98 / 2$ & 0.21 & 2 \\
\hline 1-(4-tolyl)-3-methyl-1-butyn-3-ol & 66 & & $95 / 5$ & 0.10 & 3 \\
\hline $\begin{array}{l}\text { 1-(4-chlorophenyl)- } \\
\text { 3-methyl-1-butyn-3-ol }\end{array}$ & 65 & & $98 / 2$ & 0.16 & 5 \\
\hline 1,3-diphenyl-1-propyn-3-ol & 88 & & $97 / 3$ & 0.44 & 10 \\
\hline $\begin{array}{l}\text { 1-(4-methoxyphenyl)- } \\
\text { 3-phenyl-1-propyn-3-ol }\end{array}$ & 85 & & $99 / 1$ & 0.49 & 11 \\
\hline 1-trimethylsilyl-1-propyne & 98 & & $91 / 9$ & 0.17 & 5 \\
\hline bis(trimethylsilyl)acetylene & & & & 0.28 & \\
\hline 1-phenyl-2-(trimethylsilyl)acetylene & 28 & & $95 / 5$ & 0.05 & 1 \\
\hline $\begin{array}{l}\text { [3,5-bis[(dimethylamino)methyl]- } \\
\text { phenyl ]acetylene }\end{array}$ & 98 & & & 0.03 & 9 \\
\hline \multicolumn{6}{|l|}{$\begin{array}{l}\text { 1-[3,5-bis-(dimethylamino)methyl]- } \\
\text { phenyl)-2-(trimethylsilyl)acetylene }\end{array}$} \\
\hline propargyl (dimethylamine) & 100 & & & 0.18 & 4 \\
\hline \multicolumn{6}{|l|}{ methyl propargyl sulfide } \\
\hline methyl propargyl ether & c & & & & \\
\hline 1-ethynyl-cyclohexene & 93 & & & 0.4 & \\
\hline trans,trans-1,4-diphenyl butadiene & 41 & & & 0.001 & \\
\hline 1,4-diphenyl butadiyne & $6^{d}, 49^{e}$ & & & 0.13 & $4^{f}$ \\
\hline
\end{tabular}

a Selectivity toward the alkene when quinoline (25 equiv) is added. b Selectivity toward the alkene when Catalyst II (4 wt \% Pd, 4.8 wt $\% \mathrm{Cu}$ ) is used. ${ }^{\mathrm{c}}$ Polymerization of the substrate. ${ }^{\mathrm{d}}$ Maximum yield of the enyne. e Maximum yield of the cis, $\mathrm{Cis}-\mathrm{diene} .{ }^{f} \mathrm{r}_{\mathrm{C}} \equiv \mathrm{C}-\mathrm{C} \equiv \mathrm{C} \rightarrow \mathrm{C} \equiv \mathrm{C}-\mathrm{C}=\mathrm{C} /$

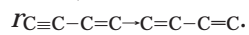

methyl propargylic ether, we observed that instead of the hydrogenated product a polymer was formed. Addition of this substrate to catalyst I in the presence or absence of hydrogen immediately results in polymerization, whereas addition of the substrate to either a silicasupported palladium catalyst, palladium salts or copper salts does not. This indicates that the combined palladium-copper phase is responsible for the polymerization.

A general property of our catalysts is that overhydrogenation is less pronounced in the semihydrogenation of disubstituted than of the monosubstituted alkynes. High yields of the cis-alkenes can be achieved and easily isolated. trans-Alkenes are accessible by metal-ammonia reduction of disubstituted al kynes. ${ }^{82}$

With catalyst I, disubstituted alkynes bearing aromatic groups can, in general, be converted to the cis-alkene with high selectivity. Variation of the substituent on the para position of the aromatic ring in the substrates 4-X$\mathrm{C}_{6} \mathrm{H}_{4} \mathrm{C} \equiv \mathrm{CC}\left(\mathrm{CH}_{3}\right)_{2} \mathrm{OH}$ did not affect the catalyst selectivity. For these substrates the reactions were quite slow and not highly selective. It was found that the presence of a bulky group such as a trimethylsilyl group, a common

(82) Reductions, Techniques and Applications in Organic Synthesis; Smith, M., Augustine, R. L., Eds.; Dekker: New York, 1968; p 95. and useful protecting group in organic synthesis, ${ }^{83} \mathrm{com}$ plicates the hydrogenation of the triple bond. For example, bis(trimethylsilyl)acetylene and 1-(3,5-bis[(dimethylamino)methyl ]phenyl)-2-(trimethylsilyl )acetylene could not be reduced, probably due to steric hindrance at the triple bond and strong competitive adsorption of the amine functions. Instead, hydrogenolysis of the carbon-silicium bond took place. However, 1-phenyl-2(trimethylsilyl)acetylene could be hydrogenated without hydrogenolysis, be it with low selectivity (28\%) toward the semihydrogenated product.

The semihydrogenation of 2-butyne-1,4-diol is remarkably selective; $99 \%$ of the alkene could be formed in a cis/trans ratio of 99/1. The commonly found undesired side products due to hydrogenolysis, condensation, and ketone formation were not observed.

With most conjugated enynes a modest reduction in bond selectivity is noted. ${ }^{2}$ While the isolated triple bond often shows nearly complete selectivity, the enyn system gives only $85-90 \%$ bond selectivity. ${ }^{84}$ Reduction of 1-ethynylcyclohexene using a palladium-on-strontium carbonate gave 1-vinylcyclohexene in $81 \%$ yield, ${ }^{85}$ while over the

(83) Green, T. W. Protective Groups in Organic Synthesis; J ohn Wiley \& Sons: New York, 1981.

(84) Marvell, E. N.; Tashiro, J . J . Org. Chem. 1965, 30, 3991. 
Lindlar catalyst $86 \%$ of the diene along with $8 \%$ of 1-ethylcyclohexene and $6 \%$ of starting material was found Our catalyst I gave $93 \%$ of the desired diene al ong with 1-ethylcyclohexene and isomerization products.

The addition of quinoline ( 25 equiv) caused a notable increase in selectivity toward the alkene, especially for substrates that gave relatively low alkene yields, such as 1-ethynyl-1-cyclohexanol and 1-phenyl-1-butyn-3-ol. The cis/trans ratio remained high.

\section{Conclusions}

When the reaction between lithium di (4-tolyl)cuprate and a palladium salt is performed in the presence of silica, small, well-mixed palladium-copper particles are deposited on the support surface. The simultaneous reduction and deposition of the metals in the liquid-phase is fast and can be performed under mild conditions. No high-temperature treatment is necessary. This makes this preparative method particularly useful for the synthetic chemist. The silica-supported palladium-copper catalyst is selective in the liquid-phase semihydrogenation of various monosubstituted alkynes giving high yields of the ol efin (up to 99\%) with excellent activity. In addition, the catalyst shows good selectivity toward cisolefins in the hydrogenation of disubstituted alkynes. The performance of the catalyst is slightly better than that of the Lindlar catalyst (higher maximum attainable ol efin yield, higher $r_{s} / r_{0}$ ) and it seems to be better reproducible. The semihydrogenation can best be performed in protic solvents. Addition of quinoline or potassium hydroxide to the reaction mixture or air exposure of the catalyst before use increases the selectivity toward the formation of the alkene and leads to much higher $r_{s} / r_{0}$.

\section{Experimental Section}

General Methods. All reactions were performed in an atmosphere of nitrogen using standard Schlenk techniques. Toluene, $\mathrm{C}_{6} \mathrm{D}_{6}, \mathrm{Et}_{2} \mathrm{O}$, and pentane were freshly distilled from sodium benzophenone-ketyl. All other solvents were used as received.

The support material used was silica OX-50 (surface area $50 \mathrm{~m}^{2} / \mathrm{g}$ ) purchased from Degussa. The silica was boiled in doubly distilled water and dried in vacuo at $200{ }^{\circ} \mathrm{C}$ for 3 days (to increase the amount of silanol groups) prior to use. In later work, Davisil 643 was used because its handling properties are better and it contains sufficient silanol groups to make boiling in water superfluous.

$\mathrm{Pd}(\mathrm{OAc})_{2}$ (47.35\% metal content) was used as purchased from Degussa. M ost of the substrates and other reagents were purchased from Acros and were distilled prior to use. Other substrates were prepared according to literature methods ${ }^{57-63}$ and purified by Kugelrohr distillation. All substrates were analyzed by GC, GC/MS, and ${ }^{1} \mathrm{H} N M R$ and ${ }^{13} \mathrm{C}\left\{{ }^{1} \mathrm{H}\right\} N M R$ spectroscopy prior to use. The organocopper compound $\left[\mathrm{Cu}_{2}-\right.$ $\mathrm{Li}_{2}\left(4-\mathrm{tolyl}_{4}\left(\mathrm{Et}_{2} \mathrm{O}\right)_{2}\right.$ ] was prepared according to literature procedures ${ }^{64,65}$ and analyzed by ${ }^{1} \mathrm{H}$ NMR spectroscopy.

NMR spectra were recorded on 200 and $300 \mathrm{MHz}$ spectrometers at ambient temperature. GC and GC/MS analyses were performed using capillary columns and flame ionization detection. Product yields were determined by peak-area analysis since response factors for the substrates and products were found to be virtually identical. TEM-EDAX was performed on an electron microscope equipped with a field emission gun. XPS was performed on a Vacuo-Generators Microtech Ltd Mt 500 unit combined with a CLAM-2 analyzer. X-ray absorption spectra of the Pd K-edge were taken at ambient temperature

(85) Robins, P. A.; Walker, J . J . Chem. Soc. 1952, 642. at Daresbury Wiggler station 92 . Both $\mathrm{Pd}(1.92$ wt \%)Cu(1.75 wt $\%) / \mathrm{SiO}_{2}$ and $\mathrm{Pd}(1.95$ wt $\%) \mathrm{Cu}(3.10$ wt $\%) / \mathrm{SiO}_{2}$ were measured directly after preparation (i.e., in the presence of chemisorbed hydrogen). The final EXAFS function was attained by averaging the individual background-subtracted and normalized data (three scans). The final fit parameters were obtained after a full optimization of all parameters in $\mathrm{k}^{0}$ weighing.

Details of the TEM-EDAX, XPS, and EXAFS analyses have been added as Supporting I nformation.

Preparation of Organometallic Complexes. [Li(4tolyl) $]_{n}$. To a solution of 4-iodotoluene $(8.76 \mathrm{~g}, 40.2 \mathrm{mmol})$ in toluene (ca. $30 \mathrm{~mL}$ ) was added 1.05 equiv of $n$-butyllithium at $0{ }^{\circ} \mathrm{C}$. The resulting white suspension was stirred for $30 \mathrm{~min}$, after which the slightly yellow solution was decanted. The white residue was washed with pentane $(5 \times 50 \mathrm{~mL})$ and dried in vacuo. The white solid was dissolved in $\mathrm{Et}_{2} \mathrm{O}(30 \mathrm{~mL})$, and the solution was centrifuged to deposit undissolved impurities. The clear solution was decanted and after evaporation of the solvent a white solid was obtained: yield $3.70 \mathrm{~g}(94 \%)$.

[Cu $\mathbf{C u}_{4}$ (4-tolyl) $)_{4}$. To a stirred suspension of $\mathrm{CuBr}^{86}(2.09 \mathrm{~g}$, $14.6 \mathrm{mmol}$ ) in $\mathrm{Et}_{2} \mathrm{O}$ at $-30{ }^{\circ} \mathrm{C}$ was slowly added a solution of 4-tolyllithium (1.47 g, $15.0 \mathrm{mmol})$ in $\mathrm{Et}_{2} \mathrm{O}(15 \mathrm{~mL})$. The resulting suspension was stirred for $1 \mathrm{~h}$ at that temperature and then allowed to slowly warm to $0^{\circ} \mathrm{C}$ during one $1 \mathrm{~h}$. The intensely yellow precipitate, which had formed, was isolated by decantation, was washed with cold $\left(0{ }^{\circ} \mathrm{C}\right)$. $\mathrm{Et}_{2} \mathrm{O}(4 \times 50$ $\mathrm{mL}$ ) and then dried in vacuo: yield $1.34 \mathrm{~g}(60-75 \%)$.

$\left[\mathbf{C u}_{\mathbf{2}} \mathbf{L i}_{\mathbf{2}}(\mathbf{4} \text {-tolyl })_{\mathbf{4}}\left(\mathbf{E t}_{\mathbf{2}} \mathbf{O}\right)_{\mathbf{2}}\right.$ ]. To a suspension of 4-tolyl copper $(0.70 \mathrm{~g}, 5.0 \mathrm{mmol})$ in $\mathrm{Et}_{2} \mathrm{O}(25 \mathrm{~mL})$ at $0{ }^{\circ} \mathrm{C}$ was slowly added a solution of 4-tolyllithium $(0.53 \mathrm{~g}, 5.4 \mathrm{mmol})$ in $\mathrm{Et}_{2} \mathrm{O}(20 \mathrm{~mL})$ over a period of $30 \mathrm{~min}$. The resulting greenish solution was stirred for $1 \mathrm{~h}$ at $0{ }^{\circ} \mathrm{C}$ during which time a colorless precipitate of the product formed. This was isolated by decantation, washed twice with pentane and recrystallized from $\mathrm{Et}_{2} \mathrm{O}$ : yield $1.08 \mathrm{~g}(70-90 \%)$.

Preparation of Supported Palladium-Copper Catalysts. Several batches were prepared of silica-supported bimetallic $\mathrm{PdCu}$ catalysts with two different metal loadings, i.e., $\mathrm{PdCu} / \mathrm{SiO}_{2}(4 \mathrm{wt} \% \mathrm{Pd}, 2.4$ wt $\% \mathrm{Cu} ; \mathrm{Pd} / \mathrm{Cu}=1: 1$ ), catalyst I, and $\mathrm{PdCu} / \mathrm{SiO}_{2}$ (4 wt \% Pd, 4.8 wt \% Cu; $\mathrm{Pd} / \mathrm{Cu}=1: 2$ ), catalyst II.

The catalysts were prepared in a nitrogen-flushed reactor vessel of $250 \mathrm{~mL}$ volume that was equipped with three baffles (at $120^{\circ} \mathrm{C}$ ) and mechanically stirred (2000 rpm). A red-colored ultrasonically pretreated solution of palladium(II) acetate in toluene (35 mL) was added to an ultrasonically pretreated suspension of silica in toluene $(150 \mathrm{~mL})$ using a peristaltic pump. The solution was injected at the height of the stirrer. The orange suspension which formed was stirred for at least 3h. After this time, a yellow solution of the copper precursor in toluene $(50 \mathrm{~mL})$ was added by means of the peristaltic pump over a period of $30 \mathrm{~min}$ and a dark brown suspension did form. This was stirred for 3 days and then hydrogen was introduced for $3 \mathrm{~h}$ to ensure completion of the reduction process. Stirring was stopped, and the colorless solution was decanted from the settled material. The resulting black powder was washed twice with pentane and dried in vacuo at room temperature.

The activity and selectivity of all catalysts batches were tested in the hydrogenation of 3-methyl-1-pentyn-3-ol before use. Only batches of catalyst with a rate of alkyne conversion of $1.4 \times 10^{-2} \mathrm{mmol} \cdot \mathrm{s}^{-1} \cdot \mathrm{mg} \mathrm{Pd}^{-1}$ and a selectivity of at least $96 \%$ under standard conditions (vide supra) were used.The

(86) Prepared by a modified procedure from Inorganic Synthesis (Inorganic Synthesis; Wiley: New York, 1946; Vol. 2, pp 1-4): CuSO ${ }_{4}$. $5 \mathrm{H}_{2} \mathrm{O}(250 \mathrm{~g}, 1 \mathrm{~mol}), \mathrm{NaBr}(108 \mathrm{~g}, 1.1 \mathrm{~mol})$ were dissolved in $1 \mathrm{~L}$ water and heated to $65^{\circ} \mathrm{C}$. NaOH $(36.4 \mathrm{~g}, 0.9 \mathrm{~mol})$ and $\mathrm{NaHSO}_{3}(57.7 \mathrm{~g}, 0.55$ $\mathrm{mol}$ ), dissolved in $1 \mathrm{~L}$ of water was added slowly during $2 \mathrm{~h}$. The precipitate was washed consecutively with a solution of $\mathrm{NaHSO}_{3}$ (spatula point) and acetic acid ( $2 \mathrm{~mL}$ ) in $1 \mathrm{~L}$ of water, wet ether, dry ether, and distilled dry ether. The CuBr should be kept covered by solvent until the final washing. The CuBr was dried in vacuo and obtained as a white solid in $80 \%$ yield. It should be stored under nitrogen. 
catalysts that were used for the EXAFS measurements were also prepared in this way.

Catalytic Hydrogenations. The hydrogenations were performed at atmospheric hydrogen pressure in a stirred (2000 rpm) double-walled $250 \mathrm{~mL}$ glass reactor vessel equipped with three vertical glass baffles. The vessel was kept at $25^{\circ} \mathrm{C}$ by circulating thermostated water through the wall. In all hydrogenation reactions, the following procedure was used. The reactor vessel was filled with di nitrogen. The catalyst (ca. $35 \mathrm{mg}$ ) was added to the reactor followed by addition of ethanol (100 $\mathrm{mL})$. While the mixture was stirring, the (nitrogen) atmosphere was replaced by hydrogen by repetative evacuation and filling with hydrogen (five times). Although the activity of the catalysts varied with the grain size, the selectivity appeared to be constant (in contrast to what was found for a silica-supported palladium catalyst). To prevent fluctuations in the size of the conglomerates of catalyst bodies, and, thus, of the catalyst activity, the system was ultrasonically treated (5 min) and stirred for $1 \mathrm{~h}$ under hydrogen during all prereductions. Next, without stirring, a solution of the substrate $(5 \mathrm{mmol})$ in ethanol $(1.5 \mathrm{~mL})$ was added with a syringe. After the first sample had been taken, the hydrogenation reaction was started by stirring.

Hydrogen uptake was monitored using a gas buret system. Substrates and reaction products were analyzed with GC and identified with GC/MS. All catalytic reactions were performed at least twice.

The (semi)hydrogenation products were isolated for NMR and GC/MS analysis by separating the catalyst through centrifugation and concentrating the solution in vacuo. The residue was extracted with a mixture of a $75 \%$ saturated aqueous $\mathrm{NH}_{4} \mathrm{Cl}$ solution and $25 \%$ pentane. The pentane layer was separated and concentrated in vacuo. The products were obtained in yields varying from 80 to $95 \%$.

Preparation of Substrates. Analytical data of all compounds described in this section are given as Supporting Information.

3-Acetyl-3-methyl-1-pentyne. This substrate was prepared by adding $32.5 \mathrm{~g}(0.32 \mathrm{~mol})$ of acetic anhydride and a catalytic amount of phosphorous acid to $26.0 \mathrm{~g}(0.27 \mathrm{~mol})$ of 3-methyl-1-pentyn-3-ol. After being stirred at room temperature for $12 \mathrm{~h}$, the reaction mixture was washed twice with 20 $\mathrm{mL}$ of cold $\left(0^{\circ} \mathrm{C}\right)$ water. This water fraction was extracted with diethyl ether. The diethyl ether fraction and the organic product were combined, and $150 \mathrm{~mL}$ of an aqueous (10\%) $\mathrm{Na}_{2-}$ $\mathrm{CO}_{3}$ solution was added. The isolated organic fraction was again washed twice with ice-water $(20 \mathrm{~mL})$ and dried on $\mathrm{CaCl}_{2}$. After removal of the diethyl ether in vacuo $31.9 \mathrm{~g}$ of crude product was obtained. After purification by Kugel rohr distillation $\left(63^{\circ} \mathrm{C}, 76 \mathrm{mmHg}\right) 77 \%$ yield of a light yellow oil was obtained.

2-Dodecyn-1-ol and 2-Undecyn-1-ol. These substrates were prepared according to ref 61 .

1-Phenyl-1-butyn-3-ol. General Procedure. To a light yellow solution of phenylacetylene $(40 \mathrm{mmol})$ in $\mathrm{Et}_{2} \mathrm{O}(50 \mathrm{~mL})$ was added 1 equiv of $n$-butyllithium (hexane solution, 1.6 M) at $-78^{\circ} \mathrm{C}$. After being stirred for a few minutes, the dark yellow solution was allowed to warm to $0{ }^{\circ} \mathrm{C}$ using an ice bath. After $15 \mathrm{~min}$, a solution of 1.1 equiv of acetal dehyde in $\mathrm{Et}_{2} \mathrm{O}$ $\left(40 \mathrm{~mL}\right.$ ) was slowly added at $0{ }^{\circ} \mathrm{C}$ using a dropping funnel. The solution immediately turned red. After being stirred for $2 \mathrm{~h}$, the thus-formed yellow solution was quenched with a saturated ammonium chloride sol ution. The organic layer was separated from the water layer. The water layer was extracted twice with diethyl ether. The combined organic fractions were then dried on $\mathrm{MgSO}_{4}$. After filtration, the solvent was evaporated. The raw product was purified by Kugel rohr distillation at low pressure $\left(105{ }^{\circ} \mathrm{C}, 0.5 \mathrm{mmHg}\right)$ : yield $6.08 \mathrm{~g}(81 \%)$ of a yellow oil.

1-Phenyl-3-methyl-1-butyn-3-ol. The general preparation procedure described above was followed using acetone instead of acetaldehyde. After Kugelrohr distillation $\left(80{ }^{\circ} \mathrm{C} .0 .1\right.$ $\mathrm{mmHg}$ ), a white solid was obtained: yield $11.52 \mathrm{~g}(60 \%)$.

1-(4-Tolyl)-3-methyl-1-butyn-3-ol. The general preparation procedure described above was followed using acetone and 4-tolylacetylene instead of acetaldehyde and phenylacetylene. After Kugel rohr distillation $\left(85^{\circ} \mathrm{C} .0 .1 \mathrm{mmHg}\right.$ ), a white solid was obtained: yield $10.70 \mathrm{~g}(55 \%)$.

1-(4-Chlorophenyl)-3-methyl-1-butyn-3-ol. The general preparation procedure described above was followed using acetone and 4-chlorophenylacetylene instead of acetaldehyde and phenylacetylene. After Kugelrohr distillation $\left(80^{\circ} \mathrm{C} .0 .1\right.$ $\mathrm{mmHg}$ ), a white solid was obtained: yield $8.02 \mathrm{~g}(53 \%)$.

1,3-Diphenyl-1-propyn-3-ol. The general preparative procedure described above was followed using benzaldehyde instead of acetaldehyde. After Kugel rohr distillation $\left(130^{\circ} \mathrm{C}\right.$. $1 \mathrm{mmHg}$ ), a yellow oil was obtained: yield $6.49 \mathrm{~g}(75 \%)$.

3-(4-Methoxyphenyl)-1-phenyl-1-propyn-3-ol. The general preparation procedure described above was followed using 4-methoxybenzaldehyde instead of acetaldehyde. After Kugelrohr distillation $\left(176{ }^{\circ} \mathrm{C}\right.$. $\left.0.1 \mathrm{mmHg}\right)$, a white solid was obtained: yield $69.57 \mathrm{~g}(91 \%)$.

[3,5-Bis[(dimethylamino)methyl]phenyl]acetylene. The substrate was prepared according to ref 61 and deprotected by stirring with $\mathrm{KOH}$ in $\mathrm{MeOH}$ for $24 \mathrm{~h}$. Propargyl(dimethylamine), methyl propargyl sulfide, and methyl propargyl ether were prepared according to ref 60 .

Acknowledgment. This work has been performed under the auspices of NIOK, The Netherlands I nstitute for Catalysis Research, Lab Report No. UU 94-XX-YY. We thank Dr. Ir. T.A. Nijhuis (on leave in Utrecht from the Technical University Delft) for useful suggestions.

Supporting Information Available: Descriptions of anaIytical procedures and analyses of starting compounds. This material is available free of charge via the Internet at http://pubs.acs.org.

J O001246P 